\title{
The North Atlantic subpolar gyre regulates the spawning distribution of blue whiting
} (Micromesistius poutassou Risso)

\author{
Hátún, Hjálmar; Payne, Mark; Jacobsen, Jan A.
}

Published in:

Canadian Journal of Fisheries and Aquatic Sciences

Link to article, DOI:

10.1139/F09-037

Publication date:

2009

Link back to DTU Orbit

Citation (APA):

Hátún, H., Payne, M., \& Jacobsen, J. A. (2009). The North Atlantic subpolar gyre regulates the spawning distribution of blue whiting (Micromesistius poutassou Risso). Canadian Journal of Fisheries and Aquatic Sciences, 66(5), 759-770. https://doi.org/10.1139/F09-037

\section{General rights}

Copyright and moral rights for the publications made accessible in the public portal are retained by the authors and/or other copyright owners and it is a condition of accessing publications that users recognise and abide by the legal requirements associated with these rights.

- Users may download and print one copy of any publication from the public portal for the purpose of private study or research.

- You may not further distribute the material or use it for any profit-making activity or commercial gain

- You may freely distribute the URL identifying the publication in the public portal 


\section{The North Atlantic subpolar gyre regulates} the spawning distribution of blue whiting (Micromesistius poutassou Risso)

4

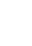

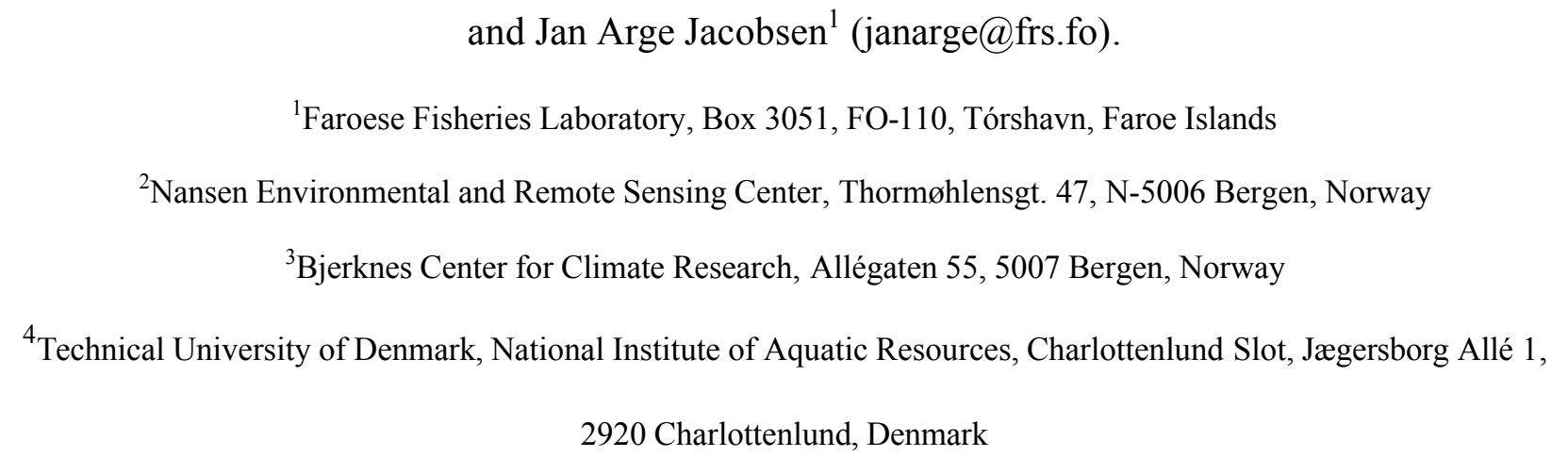

${ }^{4}$ Technical University of Denmark, National Institute of Aquatic Resources, Charlottenlund Slot, Jægersborg Allé 1, 2920 Charlottenlund, Denmark 
24 Abstract: The spawning stock of blue whiting, an economically important pelagic gadoid in the

25 North Atlantic Ocean, increased threefold after 1995. The reproductive success of the stock is

26 largely determined during the very early stages of life, but little is known about the spawning

27 dynamics of this species. We here show that the spawning distribution of blue whiting is variable,

28 regulated by the hydrography west of the British Isles. When the North Atlantic subpolar gyre is

29 strong and spreads its cold and fresh water masses east over the Rockall Plateau, the spawning is

30 constrained along the European continental slope and in a southerly position near the Porcupine

31 Bank. When the gyre is weak and conditions are relatively saline and warm, the spawning

32 distribution moves northwards along the slope and especially westwards covering the Rockall

33 Plateau. The apparent link between the spawning distribution and the subpolar gyre is the first

34 step towards understanding the reproduction variability, which currently is the main challenge for

35 appropriate management of the blue whiting stock.

37 Keywords: Long-term, Climate variability, North Atlantic Subpolar gyre, Fisheries, Spawning 38 distribution. 


\section{Introduction}

49 The northern blue whiting (Micromesistius Poutassou Risso) is a pelagic gadoid mainly

50 occupying the waters between the spawning grounds west of the British Isles and the feeding

51 areas in the Norwegian Sea (Bailey 1982). The spawning stock of blue whiting has increased

52 dramatically in the late 1990s (Fig. 1) due to a succession of strong or extremely strong year

53 classes (ICES 2007). The fishery intensified correspondingly and has in recent years been one of

54 the largest fisheries in the North Atlantic Ocean (ICES 2007). Concurrent large changes have

55 occurred in the ocean circulation in the north-eastern Atlantic (Hakkinen and Rhines 2004),

56 resulting in a rapid temperature and salinity increase west of the British Isles after the mid-1990s

57 (Hatun et al. 2005; Figs. 1 and S1). Noting the tight temporal correlation between these events,

58 we here ask whether the changes in marine environment and the blue whiting stock are causally

59 related.

60 Possible causal relations are probably complex as the environment influences many ecological

61 components simultaneously. Blue whiting are sensitive to temperatures and salinities during the

62 spawning period (Schmidt 1909), and the main spawning grounds are located west of the British

63 Isles (Fig. 2), where large oceanographic changes are known to take place (Holliday 2003).

64 The water-masses of the north-eastern Atlantic at different depths have different origins with

65 their own recognizable planktonic fauna or flora, according to their physical, chemical,

66 biochemical or biological features (Fraser 1961). The subpolar gyre controls the flow trajectory

67 of the North Atlantic Current (NAC) in the north-eastern Atlantic. When the gyre is strong and

68 extends far eastwards, a branch of the NAC peels off into the Rockall Trough, dragging cold and

69 low-salinity subarctic waters over the Rockall Plateau (Fig. 3a). When the gyre weakens and

70 shifts westwards, it allows subtropical water to spread north and west (Fig. 3b), resulting in much 
71 warmer and more saline conditions. The strength of the subpolar gyre, and thus the hydrographic

72 conditions in the Rockall region, has been represented by a so-called gyre index (Hatun et al.

73 2005; Fig. S1)

74 Since blue whiting are sensitive to hydrography while spawning in a region characterized by

75 large water mass exchanges, one might expect that the marine climate must influence the

76 spawning distribution of blue whiting. The blue whiting fishery has historically been most

77 intensive along the European continental slope, primarily near the Porcupine Bank, but also west

78 of the Hebrides, as illustrated in Fig. 2. These areas are typically thought of as the main spawning

79 grounds of blue whiting (Monstad 2004). However, investigations of blue whiting larvae before

80 the fishery commenced in the late 1970s indicated, on the other hand, that the Rockall Plateau

81 was the principal spawning ground, as opposed to the Porcupine Bank (Henderson 1957; Fig. 2).

82 Thus, there are apparent conflicting statements about the spawning areas of blue whiting and only

83 limited explanations for their spawning dynamics (Bartsch and Coombs 1997; Skogen et al.

84 1999).

85 The dominance of the Rockall Plateau as a spawning ground was particularly pronounced

86 during the warm early 1960s, but the spawning distribution shifted southwards towards the

87 Porcupine Bank during the late 1960s (Bainbridge and Cooper 1973) when temperatures

88 decreased in the region (Fig. 1). The stark contrast between the spawning distributions reported

89 during the mid-nineteenth century warm period and the cold early 1990s (Fig. 2) suggests a link

90 between the marine environment and the spawning dynamics of blue whiting. Bainbridge and

91 Cooper (1973) postulated that the source of this variable distribution probably involved

92 environmental variables; that the source of this variability might be found in regions remote from

93 the spawning areas and that they might affect the stock after a considerable time lag. They also 
94 stated that further progress on this topic had to await better environmental data over a longer run 95 of years.

96 Since that work was published, we have witnessed the large mid-1990 changes in both the

97 recruitment (and stock size) of blue whiting and also in the marine climate. Additionally, physical

98 time series are now available that link the previous (1960s) warm period to the recent (post-1995)

99 warm period. It is therefore timely to look at the previous and the present spawning distributions

100 and to collectively examine these in light of the oceanographic changes that have taken place.

101 In trying to approach the fundamental question of a causal link between marine climate and

102 blue whiting reproduction, we here limit the aim to document a link between the spawning

103 distribution of blue whiting and the variable marine environment in this region. The working

104 hypothesis we explore here is that the spawning distribution is predominately controlled by the

105 marine climate conditions to the west of Great Britain and Ireland, moving north along the

106 European continental slope and west over the Rockall Plateau during (saline and warm) periods

107 when the subpolar gyre is weak, and south towards the Porcupine Bank during (fresh and cold)

108 periods when the gyre is strong.

109

\section{Material and Methods}

\section{The NISE hydrographic database}

112 A comprehensive hydrographic (temperature and salinity) dataset has been compiled in 113 association with the project Norwegian and Iceland Seas Experiment (NISE). The basis of this

114 dataset is the public database maintained by the International Council for the Exploration of the

115 Seas (ICES) (www.ices.dk). This database is then supplemented by data from the Marine

116 Research Institute, Iceland; Institute of Marine Research, Norway; the Faroese Fisheries 
117 Laboratory; the Arctic and Antarctic Research Institute, Russia and Geophysical Institute,

118 University of Bergen, Norway and the World Ocean Circulation Experiment

119 (WOCE)(www.woce.org). The data used here (post-1980) are generally measured by CTD

120 (Conductivity, Temperature, Depth) sondes, but data from the Argo float array

121 (www.usgodae.org) have also been included. Data quality control has been performed by each

122 data contributor, but some additional data cleaning has been applied to the dataset by NISE

123 (Nilsen et al. 2008).

125 Acoustic biomass survey data

126 Acoustic abundance estimates of blue whiting in the spawning areas from 1981 and onwards

127 were obtained from the annual blue whiting surveys reported in the ICES "Northern Pelagic and

128 blue whiting Working Group" reports (ICES 2007) as biomass (tons) averages over $0.5^{\circ}$ latitude

$129 \times 1^{\circ}$ longitude (1981-2001).

130 During the standardized surveys, continuous acoustic recordings of fish and plankton were 131 collected along the cruise tracks using calibrated $38 \mathrm{kHz}$ echo sounder systems. The acoustic

132 recordings (area backscattering by each nautical mile, $\mathrm{s}_{\mathrm{A}}$ ) were allocated to blue whiting based on

133 the composition of the trawl catches taken whenever needed to identify the acoustic scatterers as

134 well as by visual scrutiny of the echo recordings, whereafter biomass estimates were calculated

135 by multiplying abundance in numbers by the average weight of the fish in each statistical square

136 (Foote 1987; Toresen et al. 1998).

137 The annual surveys were carried out from mid-March to mid-April with less than two weeks

138 difference in timing. The error introduced by a variable timing in relation to the spawning

139 progress should be minor compared to the large spatial shift revealed by these data. The surveys

140 are widely regarded as representing the actual spawning distribution and not the pre or post- 
141 spawning migrations. The most recent data (after 1995) originate from joint international surveys,

142 while the older data are obtained predominately from Norwegian surveys, with two years from

143 Russian surveys.

144 Furthermore, the fish present in the area at spawning time are mostly actively spawning blue

145 whiting. The proportions of immature fish in the spawning area varied in most of the years

146 between nil and 10\%, with some exceptions, e.g. around $15 \%$ in 2001,1998 , and 1989, mainly

147 due to rich year-classes contributing as young fish (1 or 2 group) in the area (ICES 2007). The

148 survey coverage included the Porcupine Bank area, the shelf edge west of the Hebrides all years

149 except in 1982, 1997 and 2001. The Rockall Plateau area has been regularly covered since 1998,

150 but only occasionally during the 1980s and early 1990s (Fig. 4a).

151

152 Blue whiting larvae data

153 Blue whiting larvae data were obtained from the Continuous Plankton Recorder survey (CPR)

154 (Reid et al. 2003). The survey is a monitoring programme using a high-speed plankton sampling

155 machine that is towed at 10-m depths behind ships of opportunity on standard routes each month

156 of the year. The data presented here are obtained from tows performed by Ocean Weather Ships

157 patrolling the waters west of the British Isles from 1951 to 1970 (Bainbridge and Cooper 1973).

158 These data have kindly been reworked and made available to us by Sir Alister Hardy Foundation

159 for Ocean Science (www.sahfos.ac.uk).

160

\section{$161 \quad$ Fisheries catch statistics}

162 Under the NEAFC (North Eastern Atlantic Fisheries Commission, www.neafc.com) scheme, 163 vessels report to their respective (national) Contracting Parties and this information is shared via 164 the NEAFC Secretariat's database. The blue whiting catch statistics applied here are obtained 
165 from this database. The data are available as monthly values of the total catch gridded onto $0.5^{\circ}$

166 latitude $\mathrm{x} 1^{\circ}$ longitude rectangles and differentiated for each national fleet. Data are exclusively

167 used from the Norwegian fleet, as the spatial distribution of this fleet was not limited by political

168 regulations. The other major fishing nations for blue whiting, the Faroe Islands and Russia had

169 only limited or no access, respectively, to European Union waters during most of the period from

1701980 to 2007 . The fishery in spring is focused on spawning blue whiting. We assume that the

171 figures given represent catches of adult spawning blue whiting with proportions of immature fish

172 comparable to those in the surveys reported above, as the fishery tend to selectively concentrate

173 on large (adult) and thus mature fish.

175 Regional gyre index

176 A regional gyre index, based on simulated sea surface height, has been produced here. This is

177 done by repeating the analysis of Hatun et al. (2005), while limiting the analysis to a

178 geographical region in the north-eastern Atlantic Ocean $\left(54-66^{\circ} \mathrm{N}, 30-0^{\circ} \mathrm{W}\right)$. The regional index

179 presented here is similar to the one presented by Hatun et al. (2005), except from a dip in the

180 mid-1980s, which is largely ascribed to dynamics in the Irminger and Labrador Seas. The

181 employed numerical Ocean General Circulation Model (OGCM) is the Nansen Center version

182 (Bentsen et al. 2004; Drange et al. 2005) of the MICOM (Miami Isopycnal Coordinate Ocean

183 Model) (Bleck et al. 1992), forced with daily mean NCEP/NCAR (Kalnay et al. 1996) reanalyses

184 of fresh water, heat, and momentum fluxes for the period 1948-2003. Since this model system

185 terminated in 2003, the gyre index has been extended to 2006 using satellite altimetry (Hakkinen 186 and Rhines 2004, updated). 


\section{Use of spatial data transformations}

190 The biological and physical data sets described above are generally scattered in both time and 191 space, with variable resolution, making direct comparisons difficult. The survey biomass and the

192 hydrographic data are most densely distributed along the European continental slope (roughly

193 meridional) (Fig. 4), while the CPR larvae data are most densely distributed along track lines

194 fanning out westwards from the continental slope towards Hatton Bank (Bainbridge and Cooper

195 1973). To enable meaningful comparisons, each dataset has been transformed onto a common 196 axis, following the regions with densest data coverage.

197 To illustrate meridional shifts in the survey biomass and the hydrography along the European 198 continental slope, these data have been transformed onto a curvilinear axis ( $s$-axis) tracking the

199 high density of observations along the continental shelf-edge, starting within the Porcupine

200 Seabight in the south $\left(50.5^{\circ} \mathrm{N}\right)$, and continuing with points along the slope north to $61^{\circ} \mathrm{N}$, west of

201 Shetland (Fig. 4). To illustrate blue whiting larvae distribution shifts on-off the Rockall plateau,

202 the CPR larvae data are transformed onto a rectilinear axis ( $r$-axis) extending from the

203 continental slope north-westward towards the Hatton Bank (Fig. 8a).

204 The value at a given position $x$ along these axes is calculated as a weighted average of the 205 available observations within a truncation radius $\left(r_{0}\right)$ around this position. If too few observations

206 are available near a position $x$, the truncation leaves the transformed value void, instead of having

207 it represented by only a few too remotely positioned observations. The transformed value at 208 position $x$ can be written as:

210

$$
\hat{D}(x)=\frac{\sum_{i}^{N} D_{i} w\left(d_{i}\right)}{\sum_{i}^{N} w\left(d_{i}\right)}
$$


212 where $N$ is the number of observations $\left(D_{i}\right)$ within the truncation radius $r_{0}$, and $w$ is a weight,

213 which is a function of the distance $d_{i}$ from position $x$. A Gaussian weighting function was used,

214 as it gives a smooth distribution and its properties are easily understood. This weight is given by:

$$
w(d)=\exp \left(\frac{-d^{2}}{2 \tau^{2}}\right)
$$

218 where $d$ is the distance between position $x$ and the location of the observation, and $\tau$ is the width

219 of the filter. Since we are interested in shifts in distributions more than the inter-annual

220 abundance variations, the biological observations have been normalized by the annual along-axis 221 mean.

223 Results

\section{Meridional shifts}

225 Survey biomass and the subpolar gyre

226 Meridional shifts in the concentration of spawning blue whiting along the European

227 continental slope ( $s$-axis) are seen to co-vary with the dynamics of the subpolar gyre (Fig. 5a).

228 For transforming the survey data onto the $s$-axis, these biomass observations are regarded as data

229 points located in the centre of each $0.5^{\circ}$ latitude $\times 1^{\circ}$ longitude square, as presented in the ICES

230 reports. The Gaussian filter width $(\tau)$ and the truncation radius $\left(r_{0}\right)$ were both $100 \mathrm{~km}$, as this is

231 comparable to the size of each data square. The denominator in equation (1) removes the effect of

232 high or low survey coverage in an area, and the obtained value is thus consistent and comparable 
233 along the entire $s$-axis. This gives a normalized Gaussian-weighted mean-density of blue whiting

234 observed within a 200-km wide swath along the $s$-axis, including the spawning period every year 235 since 1981 (Fig. 5a).

236 The regional gyre index is plotted onto the survey biomass map (black curve Fig. 5a), together 237 with the salinity (red curve) observed along a section (Ellett Line; Fig. 4b) extending from the 238 continental shelf towards the Rockall Bank across the northern Rockall Trough (Holliday et al.

239 2000). The salinity is averaged over depth range $0-800 \mathrm{~m}$, and the time series illustrates the

240 strong subpolar gyre related exchanges of water masses around Rockall, as previously

241 demonstrated (Hatun et al. 2005). Salinity is shown since this is a more conservative tracer than 242 temperature, and thus a better indicator for oceanic advection.

243 The gyre was relatively weak in the early 1980s, the salinities were high and whilst survey

244 coverage is incomplete during this time, the available observations suggest that spawning has a 245 northerly orientation, taking place on the shelf edge west of the Hebrides $\left(\sim 58^{\circ} \mathrm{N}\right)($ Fig. $5 \mathrm{a})$. The

246 gyre intensified appreciably in the early 1990s, resulting in very low salinities and the largest

247 spawning concentrations in the Porcupine Seabight, to the far south. The sudden weakening of

248 the subpolar gyre after 1995 enforced a rapid increase in salinities and a clear northward shift of

249 spawning activity. Since about 2003 the gyre has intensified slightly, salinities have again

250 decreased and the spawning distribution has retracted somewhat toward the south. Statistical

251 analysis shows significant correlations between the location of the maximum spawning

252 concentrations on the $s$-axis and both the gyre index $(r=-0.56, \mathrm{df}=15, p=0.021)$ and the

253 average salinity on the Ellett Line $(r=0.62, \mathrm{df}=15, p=0.007)$. Similar correlations are seen

254 using the centre of mass of the distribution as the dependent variable instead of the location of the 255 maximum. 
257

258 The largest concentrations of spawning blue whiting are observed within specific salinity (Fig.

$2595 \mathrm{~b}$ ) and temperature (Fig. S2) ranges. Demonstrating this requires considerable hydrographic data

260 distributed along the southward migration route of the pre-spawners. This data material is not

261 available over the open ocean areas (Fig. 4b), and the analysis has therefore been done along the

$262 s$-axis, bearing in mind that this might not entirely represent the environment experienced by the

263 migrating fish.

264 The hydrographic data from the spawning period (March to June) were first interpolated onto

265 300-m depths using the software Ocean Data View (Schlitzer 2007). The salinity at $300 \mathrm{~m}$,

266 considered as representative of the environment experienced by spawning blue whiting (Bailey

267 1982), was then transformed onto the $s$-axis. The result was, however, not sensitive to the choice

268 of depth, since the water column is rather homogeneous after winter convection. The Gaussian

269 filter width $(\tau)$ and the truncation radius $\left(r_{0}\right)$ were both $50 \mathrm{~km}$ (see Fig. $\left.4 \mathrm{~b}\right)$. This gives salinities

270 at 300-m depths, along the continental slope from $50^{\circ} \mathrm{N}$ to $61^{\circ} \mathrm{N}$, for the spawning period every

271 year since 1981, as shown in the time-longitude (Hovmüller) plot in Fig. 5b.

272 The isohalines move south until 1995, followed by a subsequent northwards shift, resembling

273 the variability of the subpolar gyre and the survey biomass (Fig. 5a). This shift is clearest for the

27435.35 to 35.45 psu isohalines (black curves in Fig. 5b). A second point to note is that the

275 anomalies occur in pulses - one around 1990, one around 1997 and one around 2003. The two

276 latter pulses have their counterpart in the gyre dynamics, while the pulse around 1990 does not.

277 A similar analysis has been performed using temperatures (Fig. S2), leading to similar

278 conclusions: Blue whiting prefers to spawn within relatively narrow ranges of salinity (35.35- 
$27935.45 \mathrm{psu})$ and temperature $\left(9-10^{\circ} \mathrm{C}\right)$, in gross agreement with previous findings (Henderson

280 1957; Schmidt 1909).

281

282 On-off the Rockall Plateau

283

284

Hydrography

285 The above analysis suggests that a salinity range of 35.35-35.45 psu, a temperature range of 9-

$28610^{\circ} \mathrm{C}$, or similar water mass characteristics related to these hydrographic ranges, govern the

287 spawning distribution of blue whiting. If this result is generally valid, we would expect to see

288 evidence of spawning activity throughout these water bodies, not just within the relatively narrow

289 range covered by the ICES acoustic surveys considered here (Fig. 4a).

290 The mid-1990s weakening of the subpolar gyre (Hakkinen and Rhines 2004) (Fig. 5a)

291 represents, as mentioned, a particularly pronounced shift from a subarctic influenced regime to a

292 subtropical influenced regime. This period is thus used to depict the variable dynamics of the 293 system. Composite maps of salinities at $300 \mathrm{~m}$ for the low-saline pre-1995 decade (Fig. 6a) and

294 the saline post-1995 decade (Fig. 6b) illustrate that the salinity changes are even larger around the 295 Rockall Plateau than near the continental shelf. The salinity interval (35.35-35.45 psu) in which

296 most spawning is observed near the continental slope (Fig. 5b), does not cover the Rockall

297 Plateau before 1995 (Fig. 6a), but does during the decade thereafter (Fig. 6b). A similar statement

298 can be made based on temperatures (Fig. S3). Does this mean that blue whiting also spawned

299 near the bank after 1995?

300

301

302 
303

304 The distribution of the spawning-fishery provides some insight into this question. A marked

306 7). No catches of blue whiting are reported west or south-west of the Rockall Bank before 1996

307 (Fig. 7a), while very large catches are reported there after 1996 (Fig. 7b). The Norwegian fleet

308 was not greatly-limited by political regulations in the Rockall region, and should therefore be a

309 reasonably unbiased proxy for the distribution of spawning fish in this region. In the absence of

310 more reliable biological observations of blue whiting, this data is an indication of significant

311 spawning west of the Rockall Plateau after the 1995 hydrographic shift.

Rockall-continental slope larvae distribution and sea surface temperature (SST)

314 Historical observations of larvae from the CPR survey also provide insight into the presence of

315 spawning over the Rockall Plateau. CPR larvae data from the northern Rockall Trough during the

316 period 1951-1970 have been transformed onto a linear axis ( $r$-axis) from the continental slope at

$31757^{\circ} \mathrm{N}$ extending north-westwards towards the Hatton Bank (Fig. 8a), using the Gaussian

318 transformation scheme described above (eqs. 1 and 2). The Gaussian filter width $(\tau)$ and the

319 truncation $\left(r_{0}\right)$ radius were both $100 \mathrm{~km}$ (see Fig. 8a), in order to encompass a sufficient number

320 of tows without spanning too wide. Only data from the spawning period March-June have been

321 used. Currents in this region generally flow northwards parallel to the continental shelf (Fig. 3)

322 (Ellett et al. 1986) and thus perpendicular to the $r$-axis, so that drift between spawning and the

323 observation of larvae is not expected to greatly alter the east-west distribution. The analyzed data

324 shows a clear east-west meandering of the larvae concentration evident in the longitude-time

325 (Hovmüller) plot in Fig. 8b. 
326 Data regarding salinity in this region are sparse during this early period, and we are forced

327 instead to use SST as a proxy of oceanographic conditions. Comparison with the simulated gyre

328 index in recent times shows that SST represents to first order the oceanographic changes in the

329 region (Fig. S1). However, due to the spin-up period of the numerical ocean model (whose

330 integration started in 1948), the SST time series is considered to be a more reliable measure of

331 oceanographic conditions for the early 1950s-1960s period.

332 When the SST time series is plotted onto the larvae map (red curve in Fig. 8b), good

333 qualitative agreement is seen between the east-west distribution of the larvae and the average

334 SST in this region. Warmer temperatures are seen to cause a westward shift in the larval

335 distribution towards the Rockall Plateau. Statistical analysis shows a significant correlation

336 between the location of the maximum larvae concentrations on the $r$-axis and the SST $(r=-0.50$,

$337 \mathrm{df}=18, p=0.024)$. A similar correlation is seen using the centre of mass of the distribution as

338 the dependent variable.

\section{Discussion}

\section{Blue whiting distributions during a century}

342 We here show that the spawning distribution of blue whiting is determined by the

343 oceanographic conditions to the west of Great Britain and Ireland, which in turn are regulated by

344 the North Atlantic subpolar gyre. A century after Schmidt (1909) made the first mapping of the

345 blue whiting distribution, we have now begun to understand how climate and large-scale

346 oceanography shifts and warps this distribution. The first mapping was made during the coldest

347 years (1904-1908) of the twentieth century and Schmidt (1909) observed a "striking absence" of

348 fry west of the Rockall Bank, while significant amounts of fry were observed near the Porcupine 
349 Bank. The distribution of fry observed with the CPR during the rapidly warming period from

3501948 to 1955 contrasted with Schmidt's findings, as no fry were observed near the Porcupine

351 Bank, while large concentrations were observed around the Rockall Plateau (Henderson 1957).

352 The larvae concentrations decreased in the north and increased further south during the late

353 1960s, when the climate again deteriorated and temperatures declined (Bainbridge and Cooper 354 1973).

355 Using acoustic survey data along the continental slope, we have shown that spawning fish 356 were aggregating at a northerly position during the early 1980s, but shifted again southwards

357 towards the Porcupine Bank during the late 1980s and especially during the very fresh and cold 358 early 1990s. After the dramatic decline of the subpolar gyre in 1995, the fish concentrations 359 shifted about $1400 \mathrm{~km}$ northwards along the continental slope. The spawning distributions of blue

360 whiting reported here and in the literature, can therefore be better understood by putting them in a

361 century-long hydro-climatic perspective. These hydro-climatic changes have been attributed to

362 the subpolar gyre dynamics for the post-1960 period (Hatun et al. 2005), but the gyre forcing 363 might also have been dominating during the pre-1960 period, although data are too scarce to 364 show this.

366 On-off Rockall

367 In this study, we especially want to draw attention to rapid changes in the spawning 368 distribution to include the Rockall Plateau. Coverage by the acoustic surveys is inconsistent in 369 this area, and no larvae data are available to document a possible sudden increase in spawning 370 near Rockall after 1995. The fishery catch statistics, however, do indicate a marked shift after $371 \quad 1995$. 
372 Re-analyzing the blue whiting data presented by Bainbridge and Cooper (1973), while

373 focusing on the Rockall Plateau-continental slope dimension, we showed marked on-off Rockall

374 shifts during the two decades 1951-1970. Comparing this with the sea surface temperatures (SST)

375 in the region revealed consistent near-Rockall distributions during warm years, and a near-slope

376 distribution during colder years. This result is consistent with our hypothesis of intensive

377 spawning near Rockall during the warm post-1995 period. The apparent conflicting depictions of

378 the spawning distribution of blue whiting presented by Henderson (1957) and Monstad (2004)

379 can thus be explained by the fact that they represent warm and cold regimes, respectively.

\section{Hydrographic escort}

382 We have discussed the spawning dynamics in relation to temperature and salinity mostly

383 because these parameters are widely available and facilitate a century-long perspective on the

384 marine environment-blue whiting link. Henderson (1957) stated that a hypothesis of too high

385 temperatures for spawning near the Porcupine Bank during the 1950s was hardly tenable

386 considering that the same fish species also spawns in the much warmer Mediterranean Sea. In

387 this regard, it is important to understand that SST and salinity changes in the north-eastern

388 Atlantic are proxies for large water mass exchanges. Such redistribution of water masses not only

389 alters temperatures and salinities, but also chemistry and plankton contents in the ocean. The

390 indication that most spawning occurs within narrow ranges of salinities (35.35-35.45 psu) and

391 temperatures $\left(9-10^{\circ} \mathrm{C}\right)$ could therefore be an expression of pre-spawning fish seeking the

392 chemical clues or the plankton composition contained by water masses with this temperature-

393 salinity signature.

394 The spawning distribution must, irrespective of the actual guidance mechanism, be determined

395 during the late winter period when the fish is migrating southward. An instructive example of 
396 how this may work is that of mackerel (Scomber scombrus), a pelagic species with spawning

397 migration dynamics that resemble that of blue whiting. For this species it has been demonstrated

398 that the southward migrating fish swim fast when they are in cold water, but slow down when

399 they encounter warmer waters (Reid et al. 1997). This characteristic has been called

400 enviroregulation (Neill 1984). An evolutionary process may have 'programmed' this fish species

401 to deliver their eggs in a specific marine climate and fauna which maximizes the survival of their

402 offspring. If enviroregulation also governs the southward migration of blue whiting, this can

403 explain the association between hydrography and spawning distribution. For example, the

404 preferred hydrographic range does not encompass the Rockall Plateau during the low-saline and

405 cold pre-1995 decade, so pre-spawners located near the bank will continue to swim

406 southeastwards along the salinity/temperature gradient, and thus towards the Porcupine Bank.

407 Alternatively, during the post-1995 period the preferred hydrographic conditions cover the

408 Rockall Plateau, so ripe fish first entering this region will not continue to swim southward, but

409 rather start spawning.

410

\section{A coherent picture from vague components}

412 To illustrate both the long-term and the large-scale changes in the spawning distribution of

413 blue whiting, it has been necessary to utilize many, widely-differing data sources. While each

414 individual source does not provide conclusive evidence supporting our hypothesis, taken

415 together, this material gives a consistent picture of the spawning dynamics.

416 The acoustic survey biomass is associated with uncertainties due to the acoustic method itself

417 and the timing and spatial coverage of the cruises. Although individual years and details of the

418 survey distribution might be unreliable, the characteristic southward shift until the mid-1990s,

419 followed by a northward shift is probably a real signal. 
420 The similar pattern seen in the meridional shifts of isohalines along the continental slope are

421 also believable, although data from both near-shelf and more off-shore locations have been

422 included. The data coverage is sparse until 1987, but relatively good thereafter as shown with the

423 black crosses in Fig. 5b. The basic patterns discussed are not greatly influenced by data limitation

424 after 1987. Aliasing due to the seasonal cycle is found to be insignificant since the seasonal

425 salinity variability at $300 \mathrm{~m}$ is much smaller than the interannual variability. Only using data

426 during late spring-early summer (March to June) further alleviates the aliasing problem.

427 The mid-1990 salinity changes at 300-m depths were illustrated by lumping scattered

428 observations into a pre-1995 decade and a post-1995 decade, and applying an objective mapping

429 technique (Bohme and Send 2005). Although this is a crude depiction, it probably illustrates the

430 northward flush of high-salinity water in a realistic way, due to the large extent of the mid-1990s

431 salinity changes. We also feel that the extent of the mid-1990s changes in the fishery must be

432 caused by a real shift in the spawning stock, despite the fact that fishery statistics often are

433 strongly biased by mis-reporting, and that the number and efficiency of the trawlers increased

434 greatly during the mid-1990s.

435 Some doubt has been cast on how well larvae data represent spawning distribution since the

436 larvae can have drifted considerable distances since spawning (Bainbridge and Cooper 1973).

437 Furthermore, the larvae data are sampled at 10-m depths and can be significantly influenced by

438 aperture avoidance. The sampled routes towards the weather ships vary somewhat, and the

439 approach of decomposing these data onto an axis ( $r$-axis) could therefore be questioned

440 (Henderson 1957). But the close co-variability between SST and the east-west meandering of the

441 larvae distribution still lends credibility to the result. However, the very low larvae counts near

442 the continental slope during warm years do probably not reflect an absence of spawning there. It 
443 more likely reflects a northerly spawning distribution and that the eggs may have been either

444 spawned to the north of the $r$-axis, or already drifted north prior to the time of sampling.

\section{Outlook and recruitment}

447 Our ability to link the spawning distribution of blue whiting to the dynamics of the subpolar 448 gyre is perhaps the most promising result in this study. Using realistic numerical ocean models, 449 oceanographic databases and satellite-based observations (Hakkinen and Rhines 2004; Hatun et 450 al. 2005), it is now possible to better understand the dynamics of this gyre and its atmospheric 451 forcing mechanisms (Eden and Willebrand 2001). These issues are not further elaborated here, 452 but will constitute the basis for future work aiming at a better understanding of the blue whiting 453 stock dynamics.

$454 \quad$ Having established a link between the spawning distribution and the marine climate, the next 455 challenges are to explain how the changeable spawning distribution might influence the 456 recruitment to the blue whiting stock. The large shifts in the marine environment will probably 457 influence larvae growth conditions both near the continental slope and near the Rockall Plateau. 458 Assuming that the on-off Rockall Plateau variability of blue whiting spawning activity is the 459 most important mechanism underlying the pronounced recruitment variability, we suggest the 460 following causal relations. Firstly, that eggs and fry starting on the plateau will follow different 461 drift paths from those starting on the shelf, which would enlarge and diversify their nursery area 462 and thereby improve growth/survival opportunities of the larvae. Secondly, that a potentially 463 strong retention of water masses near the Rockall Bank during warm low-gyre index years 464 (Dooley 1984) might provide good local growth conditions. Thirdly, that larval development near 465 Rockall might be in closer synchrony with production cycles of key prey types (zooplankton), 466 than nearer the continental slope (Bainbridge and Cooper 1973). 
467 Differentiating between these competing hypotheses is a challenging task which should be

468 validated by i) applying hydrographic drift modeling to investigate how the initial position of

469 eggs and larvae might influence the downstream spread of larvae and the environment they

470 encounter, ii) establishing regular field studies to sample larvae growth/size and feeding

471 intensity/food content simultaneously in the spawning areas and in the downstream larval feeding

472 areas, and relate this to the ambient prey availability and the hydrographic environment and iii)

473 examining expected east-west shifts in the distribution of 0 and 1-year-old blue whiting, by using

474 annual demersal trawl surveys on the Icelandic, Faroese, and North Sea Plateaus (cf. Heino et al.

475 2008).

476 Such questions must be understood before reasonable predictions of the dynamics of the blue

477 whiting stock in a changing environment, natural or man-made, can be made.

478

479 Acknowledgements

480

481

482

483

484

485

References

486

487 Bailey, R. S. 1982. The Population Biology of Blue Whiting in the North-Atlantic. Adv. Mar.

Biol., 19: 257-355. 
489

490

491

492

493

494

495

496

497

498

499

500

501

502

503

504

505

506

507

508

Bainbridge, V., and Cooper, G. 1973. The distribution and abundance of the larvae of the blue whiting, Micromestistius poutassou (Risso), in the north-east Atlantic, 1948-1970. Bull. Mar. Ecol., 8: 99-114.

Bartsch, J., and Coombs, S. 1997. A numerical model of the dispersion of blue whiting larvae, Micromesistius poutassou (Risso), in the eastern North Atlantic. Fish. Oceanogr., 6: 141154.

Bentsen, M., Drange, H., Furevik, T., and Zhou, T. 2004. Simulated variability of the Atlantic meridional overturning circulation. Clim. Dyn., 22: 701-720.

Bleck, R., Rooth, C., Hu, D. M., and Smith, L. T. 1992. Salinity-driven thermocline transients in a wind-forced and thermohaline-forced isopycnic coordinate model of the North-Atlantic. J. Phys. Oceanogr., 22: 1486-1505.

Bohme, L., and Send, U. 2005. Objective analyses of hydrographic data for referencing profiling float salinities in highly variable environments. Deep-Sea Res. Part II-Topical Studies in Oceanography, 52: 651-664.

Drange, H., Dokken, T., Furevik, T., Gerdes, R., Berger, W., Nesje, A., Orvik, K. A., Skagseth, O., Skjelvan, I., and Østerhus, S. 2005. The Nordic Seas: An Overview. In The Nordic Seas: An integrated perspective. Edited by H. Drange, T. Dokken, T. Furevik, R. Gerdes, and W. Berger. American Geophysical Union, Washington, DC. pp. 1-10.

Dooley, H. D. 1984. Aspects of oceanographic variability on Scottish fishing grounds.

Ph.D.thesis. University of Aberdeen. pp. 1 - 154. 
509 Eden, C., and Willebrand, J. 2001. Mechanism of interannual to decadal variability of the North $510 \quad$ Atlantic circulation. J. Clim., 14: 2266-2280.

511 Ellett, D. J., Edwards, A., and Bowers, R. 1986. The Hydrography of the Rockall Channel - An 512 Overview. Proc. R. Soc. Edinb. Sect. B: Biol. Sci., 88: 61-81.

513 Foote, K. G. 1987. Fish Target Strengths for Use in Echo Integrator Surveys. J. Acoust. Soc. Am., 82: 981-987.

Fraser, J. H. 1961. The oceanic and bathypelagic plankton of the north-east Atlantic. Mar. Res. Edinb., 4: 1-48.

Hakkinen, S., and Rhines, P. B. 2004. Decline of subpolar North Atlantic circulation during the 1990s. Science, 304: 555-559.

Hatun, H., Sando, A. B., Drange, H., Hansen, B., and Valdimarsson, H. 2005. Influence of the Atlantic subpolar gyre on the thermohaline circulation. Science, 309: 1841-1844.

Heino, M., Engelhard, G. H., and Godo, O. R. 2008. Migrations and hydrography determine the abundance fluctuations of blue whiting (Micromesistius poutassou) in the Barents Sea. Fisheries Oceanography, 17: 153-163.

524 Henderson, G. T. D. 1957. Continuous plankton records: the distribution of young Gadus poutassou (Risso). Bull. Mar. Ecol., 4: 179-202. the North Sea. Bull. Mar. Ecol., 5: 105-111.

528 Holliday, N. P. 2003. Air-sea interaction and circulation changes in the northeast Atlantic. J. 
530 Holliday, N. P., Pollard, R. T., Read, J. F., and Leach, H. 2000. Water mass properties and fluxes in the Rockall Trough, 1975-1998. Deep-Sea Res., 47: 1303-1332.

ICES 2007. Report of the Northern Pelagic and Blue Whiting Fisheries Working Group (WGNPBW). ICES C.M. 2007/ACFM: 29.

Kalnay, E., Kanamitsu, M., Kistler, R., Collins, W., Deaven, D., Gandin, L., Iredell, M., Saha, S., White, G., Woollen, J., Zhu, Y., Chelliah, M., Ebisuzaki, W., Higgins, W., Janowiak, J., Mo, K. C., Ropelewski, C., Wang, J., Leetmaa, A., Reynolds, R., Jenne, R., and Joseph, D. 1996. The NCEP/NCAR 40-year reanalysis project. Bull. Amer. Meteor. Soc., 77: 437-471.

Monstad, T. 2004. Blue Whiting. In The Norvegian Sea Ecosystem. Edited by H.R. Skjoldal. Tapir, Trondheim. pp. 263-288.

Neill, W. H. 1984. Behavioral Enviroregulation's role in fish migration. In Mechanisms of migration in fishes. Edited by J.D. McCleave, G. P. Arnold, J. J. Dodson, and W. H. Neill. Plenum Press, New York. pp. 61-66.

Nilsen J. E., Hatun, H., Mork, K. A., and Valdimarsson, H. 2008. The NISE Dataset. Technical Report No.: 08-01, Faroese Fisheries Laboratory, Tórshavn.

Rayner, N. A., Brohan, P., Parker, D. E., Folland, C. K., Kennedy, J. J., Vanicek, M., Ansell, T. J., and Tett, S. F. B. 2006. Improved analyses of changes and uncertainties in sea surface temperature measured in situ sice the mid-nineteenth century: The HadSST2 dataset. J. Clim., 19: 446-469. 
550 Reid, D. G., Turrell, W. R., Walsh, M., and Corten, A. 1997. Cross-shelf processes north of 551 Scotland in relation to the southerly migration of Western mackerel. ICES J. Mar. Sci., $552 \quad 54: 168-178$.

553 Reid, P. C., Colebrook, J. M., Matthews, J. B. L., and Aiken, J. 2003. The Continuous Plankton 554 Recorder: concepts and history, from plankton indicator to undulating recorders. Prog. Oceanogr., 58: 117-173.

556 Schlitzer, R. 2007. Ocean Data View. http://odv.awi.de.

557 Schmidt, S. 1909. The distribution of the pelagic fry and the spawning regions of the gadoids in the North Atlantic from Iceland to Spain. Rapp. P-v. Réun. Cons. Int. Explor. Mer, 10: 1229.

Skogen, M. D., Monstad, T., and Svendsen, E. 1999. A possible separation between a northern and a southern stock of the northeast Atlantic blue whiting. Fish. Res., 41: 119-131.

Toresen, R., Gjosaeter, H., and de Barros, P. 1998. The acoustic method as used in the abundance estimation of capelin (Mallotus villosus Muller) and herring (Clupea harengus Linne) in the Barents Sea. Fish. Res., 34: 27-37. 


\section{Figure captions}

573 Fig. 1. Changes in the sea surface temperature (SST) in the north-eastern Atlantic (thin line) and

574 in the spawning stock biomass (SSB) of blue whiting (thick line). The annually averaged SST

575 time series is obtained from the Hadley Centre SST data set (HadSST2) (Rayner et al. 2006), by

576 averaging over a geographical box covering the north-eastern Atlantic $\left(52.5-62.5^{\circ} \mathrm{N}, 27.5-\right.$

$57712.5^{\circ} \mathrm{W}$ ). The SSB time series (ICES 2007) has been shifted three years forward in time, which

578 is the time required for new recruits to contribute to the stock biomass.

580 Fig. 2. Map of the study region, showing places referred to in the text. The gray contours show 581 the mean density of blue whiting larvae during the years 1948-1956 as reported by Henderson 582 (1961). No larvae data are available in the region west of the dashed line (southern part of the

583 Rockall-Hatton Plateau). The intensive spawning areas during the 1980s and early 1990s, as 584 reported by Monstad (2004), are shown in black along the European continental slope.

586 Fig. 3. Simplified illustration of the source flows to the Rockall Region. (a) A strong subpolar 587 gyre results in strong influence of cold subarctic water near the Rockall Plateau (subarctic state).

588 (b) A weak gyre results in a warm subtropical anomaly near the plateau (based on Hatun et al. 589 2005) (subtropical state). Abbreviations - RP: Rockall Plateau and PB: Porcupine Bank.

591 Fig. 4. Data coverage and the $s$-axis. (a) Spatial coverage of acoustic surveys (1981-2007)

592 showing the fraction coverage of each $0.5^{\circ}$ latitude $\mathrm{x} 0.5^{\circ}$ longitude square and $(b)$ number of 593 hydrographic stations with available data at 300 meter depths during the 1981-2007 period, 594 binned into the same geographical squares. Squares with no acoustical data or fewer than five 
595 hydrographic stations are colored gray. The s-axis is shown with the dots and the truncation

596 radius $\left(r_{0}\right)$ is illustrated with white thin lines. EL: Ellett Line.

598 Fig. 5. (a) Time-latitude/distance (Hovmüller) plot of normalized biomass density of blue

599 whiting along the European continental slope (s-axis, see Fig 4). The thick black curve shows a

600 gyre index based on the simulated sea surface height in the north-eastern Atlantic, and the dashed

601 black line shows an extension of this index based on satellite altimetry (Hakkinen and Rhines

602 2004, updated). The red curve shows salinity averaged over depth range 0-800 $\mathrm{m}$ at the Ellett

603 Line (Holliday et al. 2000) (see Fig 4b). White areas indicate absence of survey data. (b)

604 Hovmüller plot of salinity at 300-m depths along the $s$-axis. Only data from March to June have

605 been included. The salinity range (35.35-35.45) encompassing the densest blue whiting

606 observations in $(a)$ is emphasized with thick black lines. Available data points are illustrated with

607 small crosses.

608

609 Fig. 6. March-June temperature composites at 300-m depths for (a) the fresh pre-1995 years

610 (1986-1995) and $(b)$ the saline post-1995 years (1996-2005). The 35.35 and 35.45 isohalines (see

611 Fig. 5b) have been emphasized with thick black dashed lines. RP: Rockall Plateau.

613 Fig. 7. Distribution of adult catches of blue whiting reported by the Norwegian fleet, averaged

614 over $(a)$ the low-saline and cold years from 1989 to 1996 and $(b)$ the saline and warmer years

615 from 1997 to 2005 . The area of each dot is proportional to the amount of blue whiting fished

616 within a $0.5^{\circ}$ latitude $\mathrm{x} 1^{\circ}$ longitude rectangle centered on the dot. 
618 Fig. 8. (a) The $r$-axis (black dots) and positions with larvae data from the CPR (red dots) during

619 the period from 1951 to 1970 . The truncation radius $\left(r_{0}\right)$ is shown with the blue dashed lines. $(b)$

620 Longitude-time (Hovmüller) plot of the normalized larvae counts. The red line shows the sea

621 surface temperature (SST) as described in Fig. 1. Available data points are shown with the

622 crosses.

623

624 


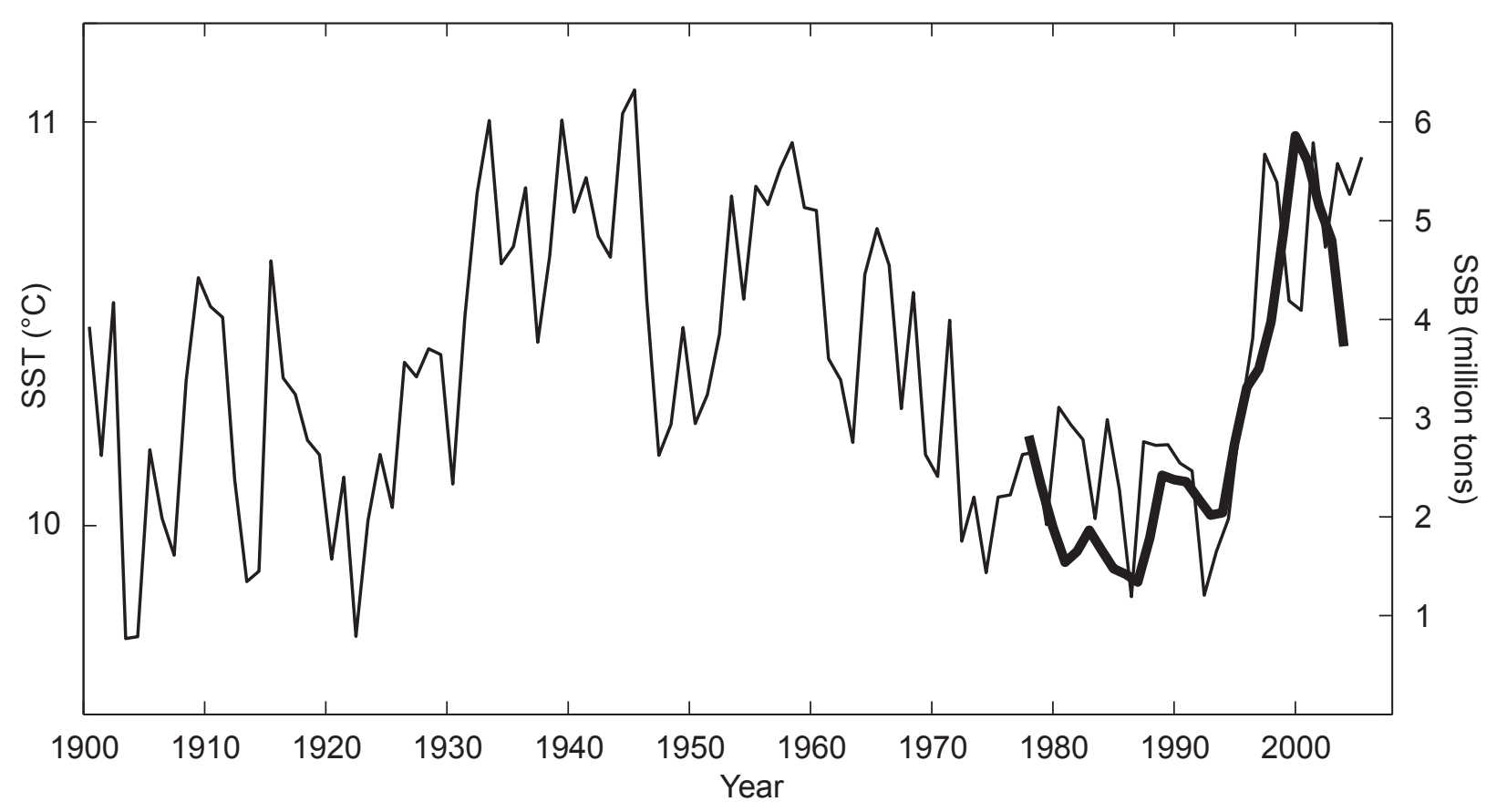




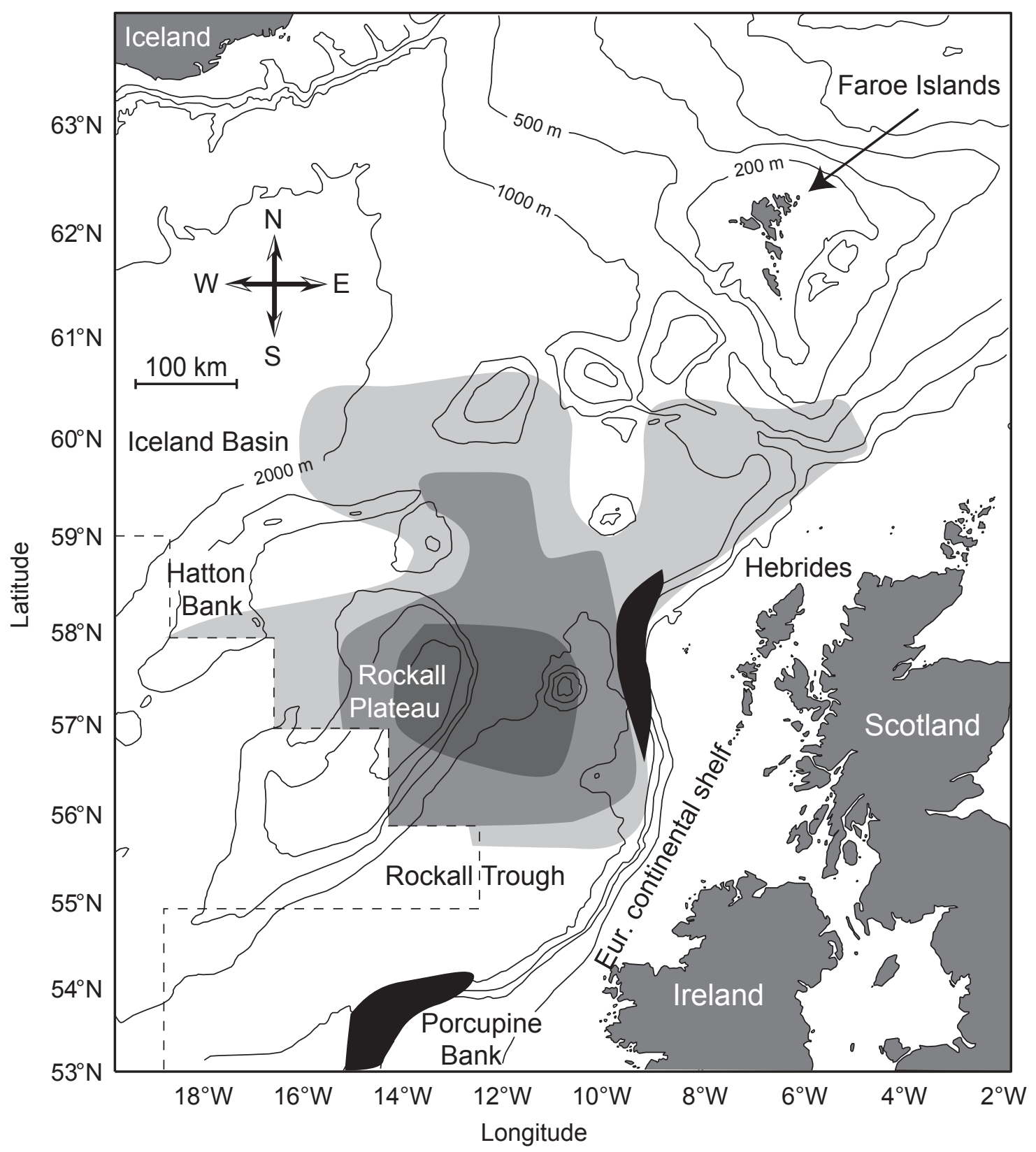



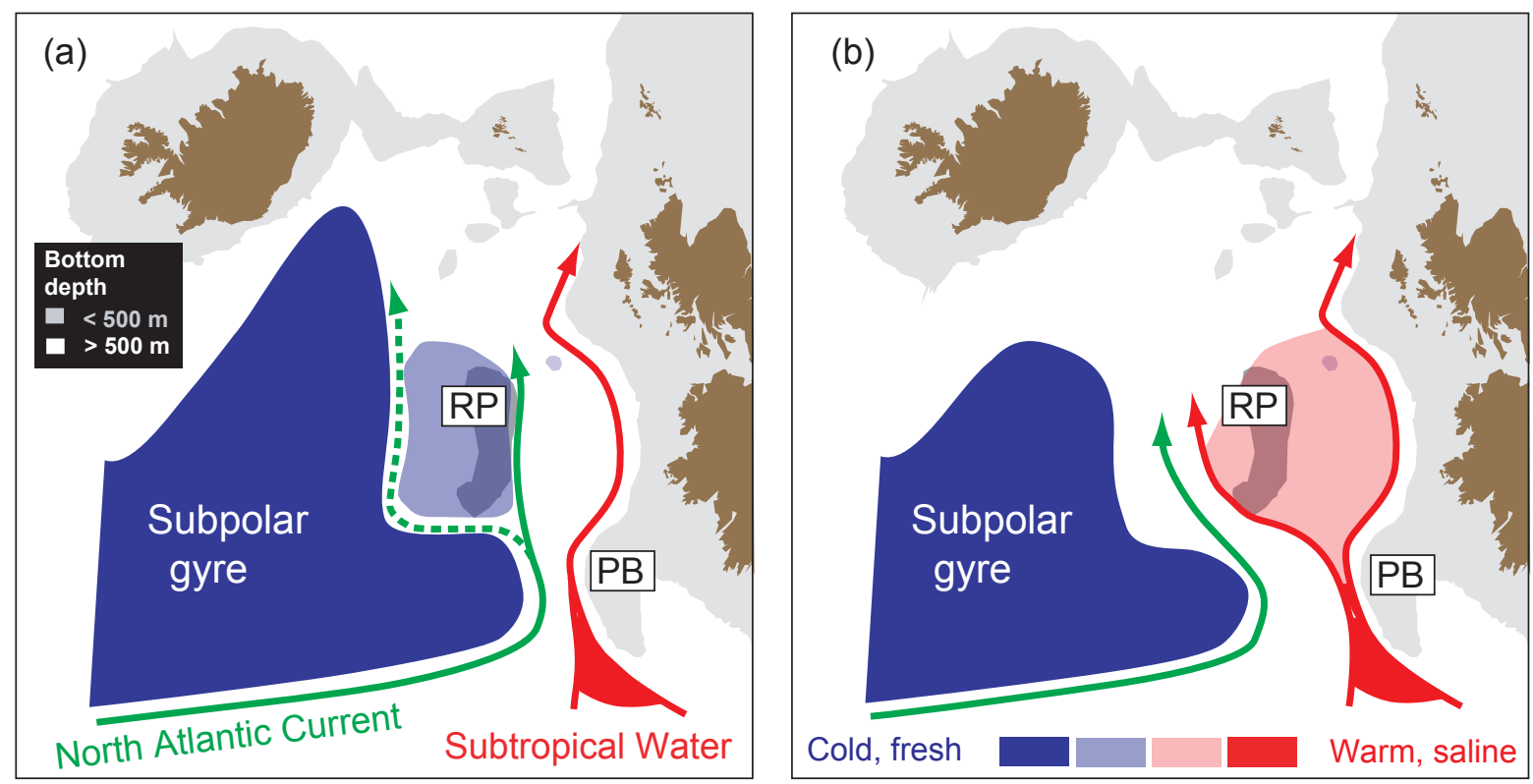


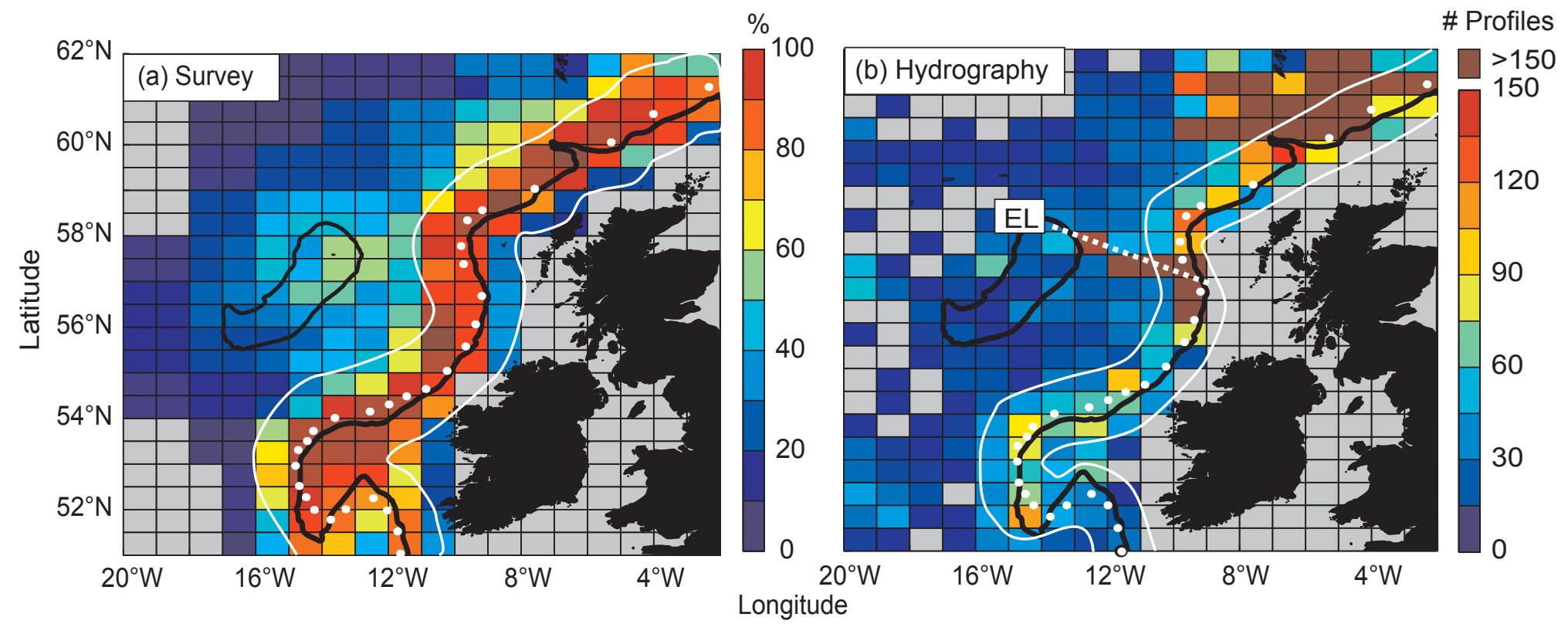



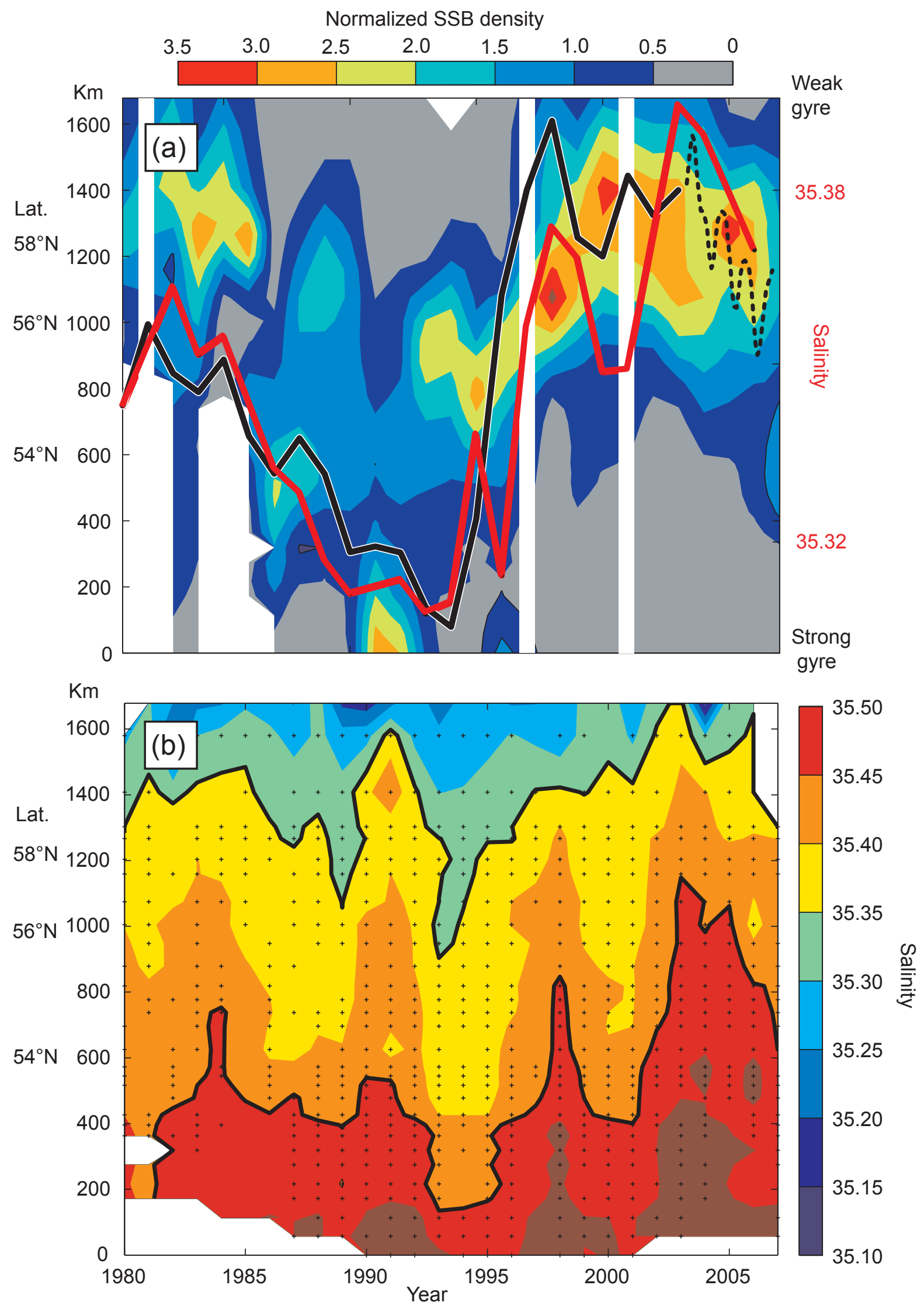
$\begin{array}{lllllllll}35.50 & 35.45 & 35.40 & 35.35 & 35.30 & 35.25 & 35.20 & 35.15 & 35.10\end{array}$

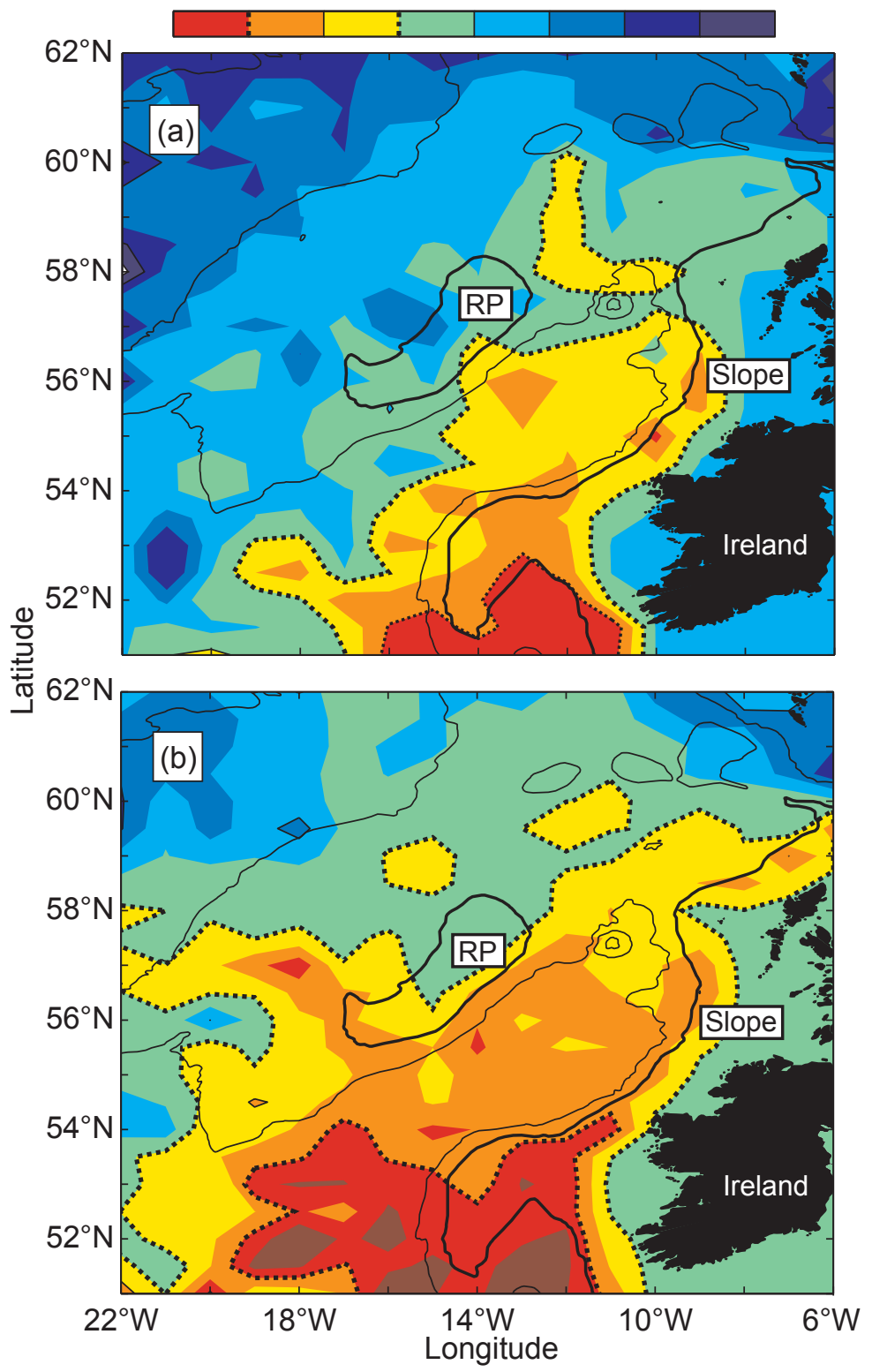




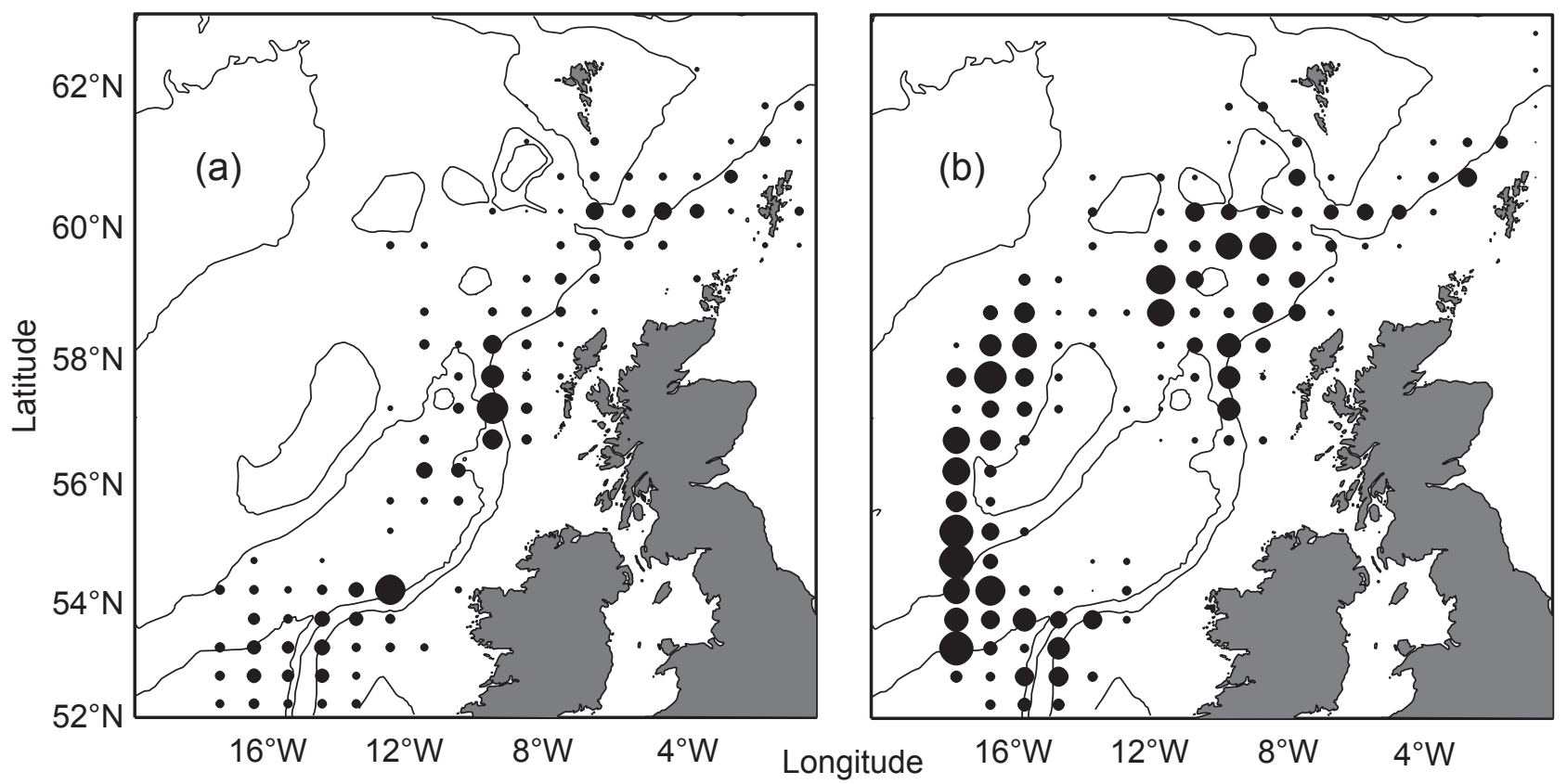




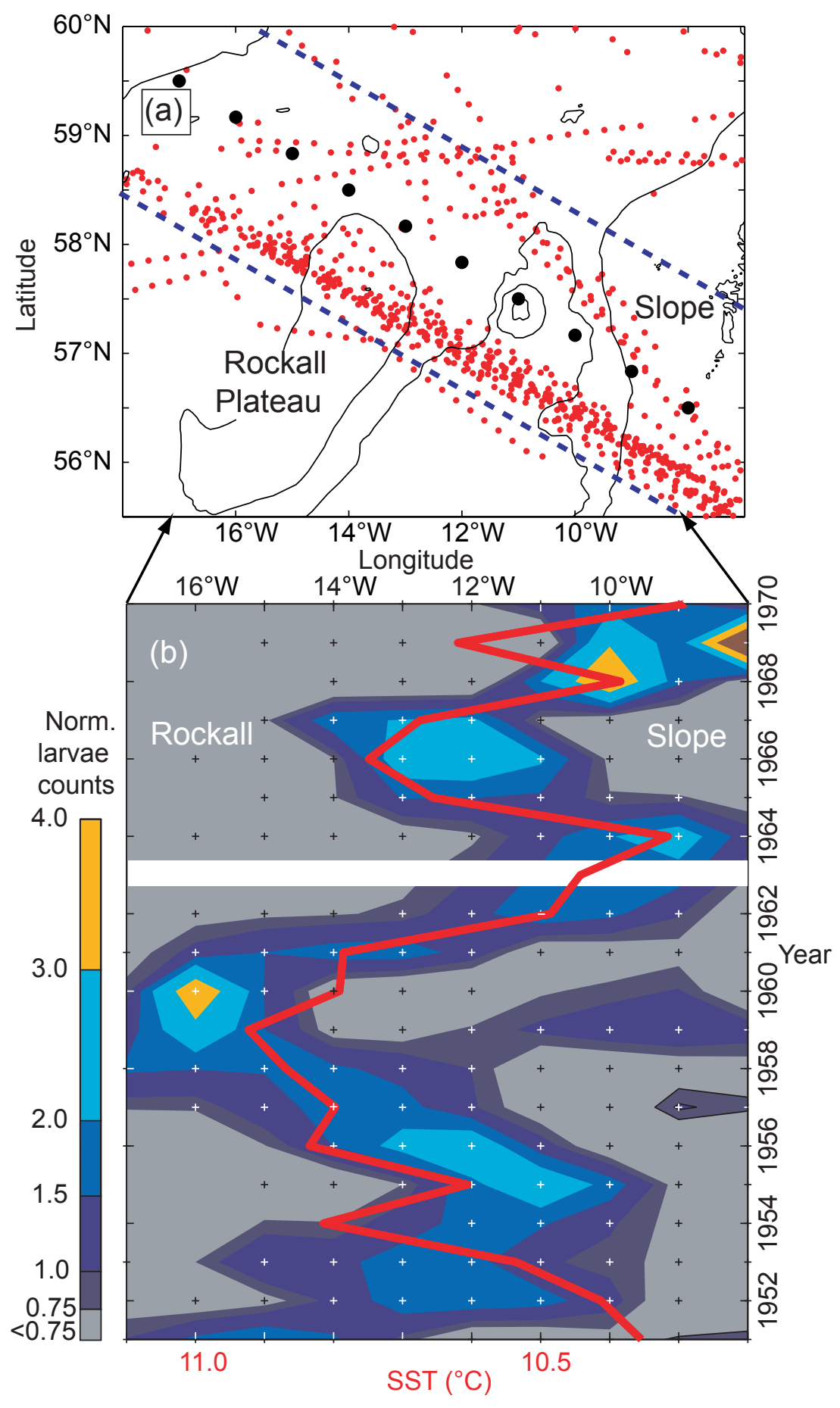

